\title{
Extracorporeal membrane oxygenation and mechanical valves: An unfriendly relationship
}

Elena Sandoval, MD, MEBCTS, María Ascaso, MD, Daniel Pereda, MD, and

Eduard Quintana, MD, PhD, FECTS, Barcelona, Spain

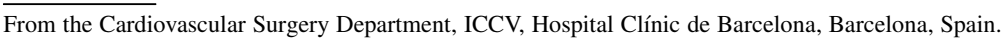

No source of funding.

Disclosures: Authors have nothing to disclose with regard to commercial support.

Presented at the 31st EACTS Annual Meeting, Nightmares in Cardiac Surgery session, Vienna, Austria, October 7-11, 2017.

Received for publication Dec 17, 2017; revisions received Feb 24, 2018; accepted for publication March 2, 2018; available ahead of print March 29, 2018.

Address for reprints: Elena Sandoval, MD, MEBCTS, Cardiovascular Surgery Department, ICCV, Hospital Clínic de Barcelona, Villarroel 170 Esc 1 5th floor, Barcelona 08036, Spain (E-mail: esandova@clinic.cat).

J Thorac Cardiovasc Surg 2018; 156:e103-5

$0022-5223 / \$ 36.00$

Copyright (C) 2018 by The American Association for Thoracic Surgery

https://doi.org/10.1016/j.jtcvs.2018.03.008

- Video clip is available online.

Extracorporeal membrane oxygenation (ECMO) can provide immediate support to a rapidly declining patient. In the presence of a mechanical heart prosthesis, however, ECMO increases the risk of thrombotic complications, necessitating an early and customized reconfiguration of support.

\section{CLINICAL SUMMARY}

A 24-year-old female patient with Marfan syndrome was admitted to our hospital with palpitations. Her medical history included a mechanical mitral valve replacement at the

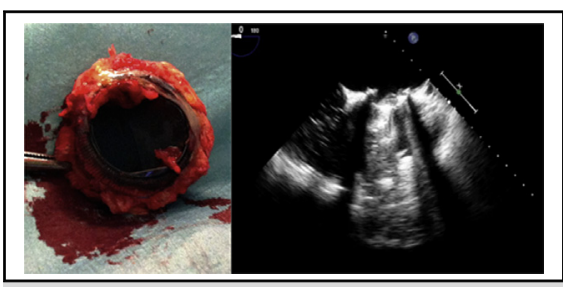

Thrombosed mitral valve prosthesis as a side effect of extracorporeal membrane oxygenation.

\section{Central Message}

Despite providing immediate support to a rapidly declining patient, ECMO increases the risk of thrombotic complications, necessitating an early and customized reconfiguration of support.

See Editorial Commentary page e107.

age of 14 years. Later, at the age of 22 years, an aortic root replacement with a mechanical prosthesis was required. She had remained free of complications for about 3 years.

Echocardiography demonstrated a severely dilated left ventricle $(84 / 78 \mathrm{~mm})$, with an ejection fraction of $10 \%$. Transplant candidacy evaluation was completed, excluding pulmonary hypertension. Although the patient was initially in stable condition, low cardiac output progressively

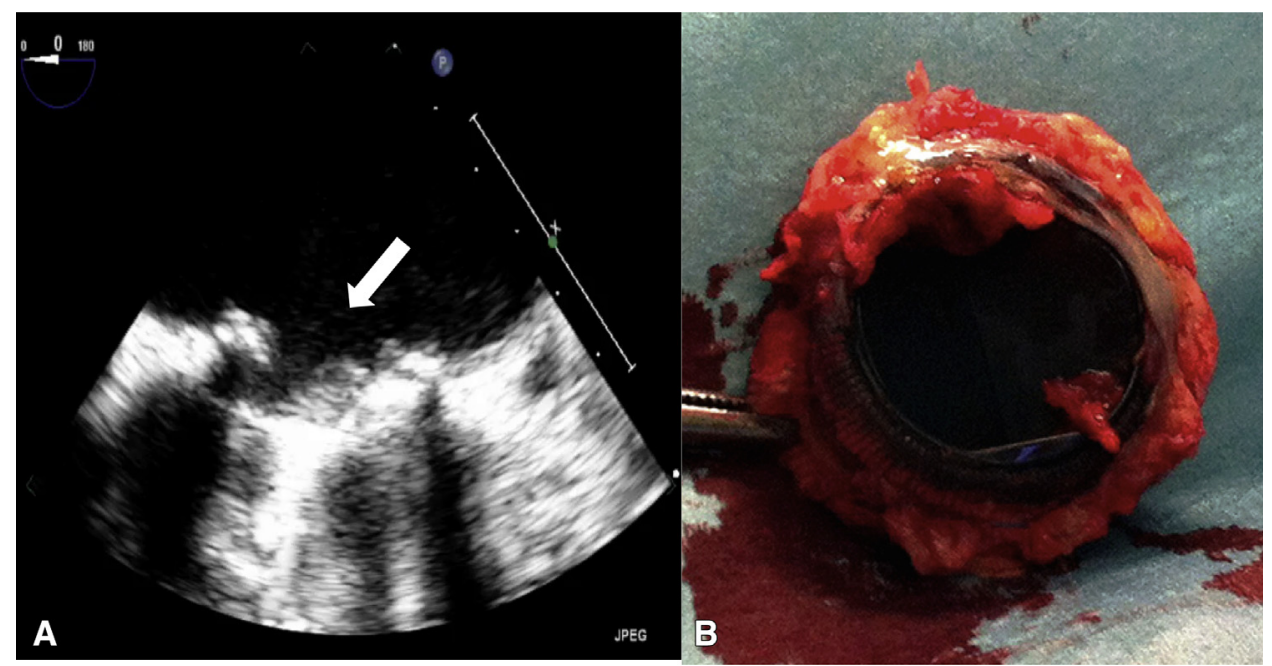

FIGURE 1. A, The thrombosed mitral prosthesis is visible on perioperative transesophageal echocardiography (white arrow). B, Photograph shows the resected mitral prosthesis with thrombus lodged in its leaflets. 

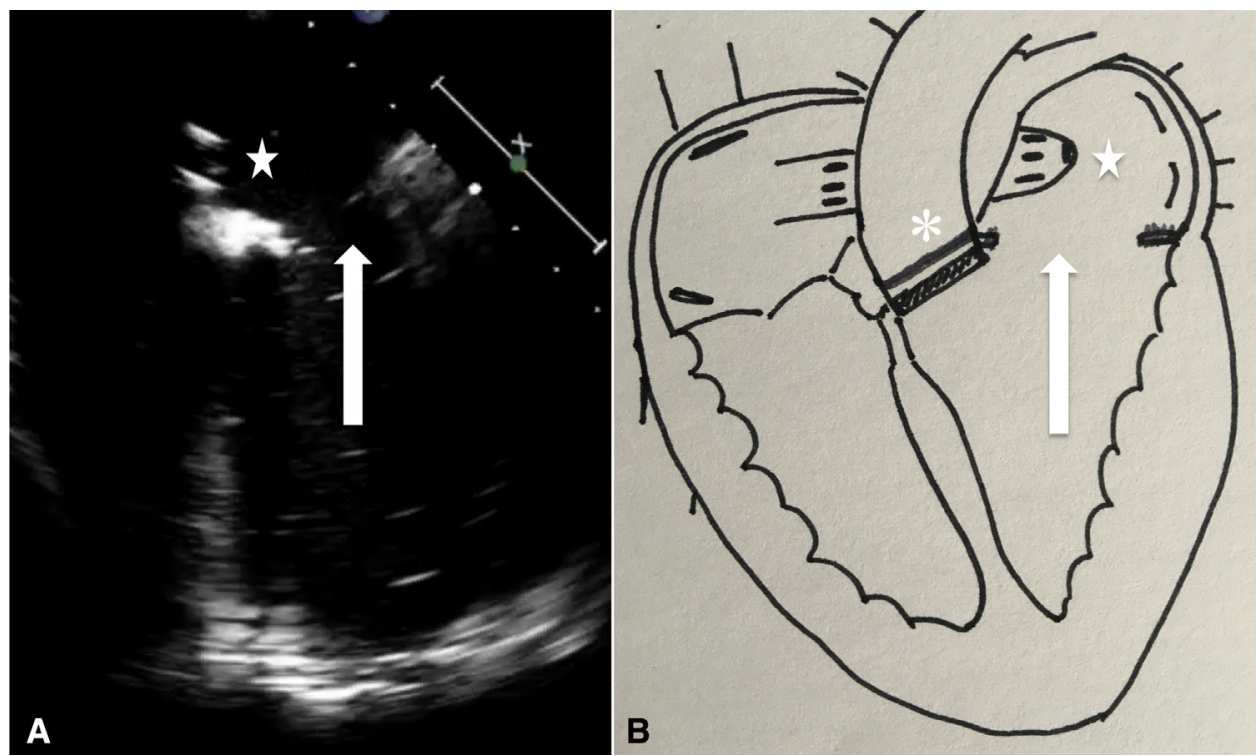

FIGURE 2. A, Postoperative transesophageal echocardiographic image shows the transseptal cannula (white star) and the space left by the removed mitral prosthesis (white arrow). B, Schematic drawing shows the final configuration of the transseptal cannula (white star), the space left by the mitral prosthesis (white arrow), and the closed aortic prosthesis (white asterisk).

developed, and she required increasing inotropic support and an intra-aortic balloon pump. She was listed for urgent transplantation. Deterioration of perfusion status led to initiation of peripheral venoarterial ECMO under local anesthesia with a $21 \mathrm{~F}$ femoral venous cannula and a 6$\mathrm{mm}$ Dacron polyester fabric graft anastomosed end to side onto the femoral artery. Adequate perfusion was immediately reestablished.

Peripheral ECMO flow was set at $2.5 \mathrm{~L} / \mathrm{min}$ to ensure left ventricular ejection and unloading and appropriate systemic oxygen delivery. Despite stable anticoagulation throughout support (partial thromboplastin time $>100$ seconds), prosthetic mitral thrombosis occurred (Figure 1, A, and Video 1), leading to pulmonary edema 4 days after initiation of ECMO support. To resolve the ongoing pulmonary edema and prevent systemic embolic complications, emergency reconfiguration of support was indicated. Because of

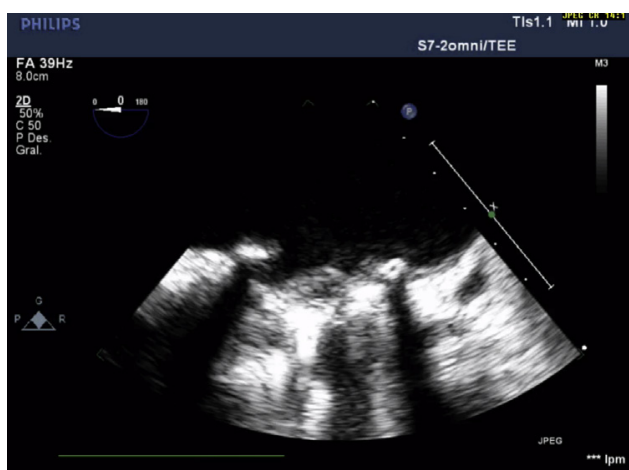

VIDEO 1. Transesophageal echocardiography demonstrates thrombosed mitral prosthesis with locked leaflets. Video available at: http://www. jtcvsonline.org/article/S0022-5223(18)30698-6/fulltext. unfavorable chest anatomy, a total artificial heart implantation was judged contraindicated.

A third-time sternotomy followed by bicaval cannulation was performed, and the ECMO circuit was switched over to cardiopulmonary bypass. The heart was arrested, and the aortic valve prosthesis was closed with a bovine pericardial patch sutured to the prosthetic sewing ring ${ }^{1}$ (Figure 2, A). We entered the right atrium and created a wide atrial septostomy. The mitral prosthesis was removed, and the raw annular edges were oversewn to minimize further thrombus formation (Figure 1, B). A new $40 \mathrm{~F}$ single-stage venous cannula was inserted through the right atrial appendage and placed transseptally so that it straddled both atria (Figure 2, B). The cardiopulmonary bypass circuit was then switched back to venoarterial ECMO through the newly inserted venous cannulation and the existing femoral arterial graft. This sole venous cannula allowed biatrial and left ventricular drainage in the absence of a mitral valve. Optimal right- and left-side unloading led to immediate resolution of pulmonary edema. The patient underwent a successful heart transplant 2 days later, and her postoperative course was uneventful.

\section{DISCUSSION}

ECMO as a bridge to transplant in the presence of mitroaortic mechanical valves increases the risk of thromboembolic events and secondary pulmonary edema. Patients not suited to total artificial heart therapy may still be safely bridged to transplant. A radical and timely reconfiguration of support by means of elimination of the mitral valve prosthesis, ${ }^{2}$ neutralization of native systemic flow, and atrial septostomy for central ECMO continuation is proposed. 


\section{References}

1. Cohn WE, Frazier OH. The sandwich plug technique: simple, effective, and rapid closure of a mechanical aortic valve prosthesis at left ventricular assist device implantation. J Thorac Cardiovasc Surg. 2011;142:455-7.

2. Slaughter MS, Pagani FD, Rogers JG, Miller LW, Sun B, Russell SD, et al; Heart Mate II Clinical Investigators. Clinical management of continuous-flow left ven tricular assist devices in advanced heart failure. J Heart Lung Transplant. 2010; 29(4 Suppl):S1-39. 